\title{
artigo
}

Franco da Silva, J.ı.; Pereira, J.B.; Coutinho, S.E.D.; França, J.R.F.S.; Oliveira, I.C.C.; Carmo, A.P.; Ramalho, E.L.R.;

O lúdico como estratégia no cuidado no olhar da criança hospitalizada

\section{O lúdico como estratégia no cuidado no olhar da criança hospitalizada}

\author{
Playfulness as a strategy in caring for hospitalized children \\ El juego como una estrategia de cuidado de niños hospitalizados
}

\begin{abstract}
RESUMO
Este artigo objetiva analisar o olhar de crianças hospitalizadas acerca do lúdico como estratégia no cuidado. Trata-se de um estudo exploratório qualitativo do tipo observacional participante, realizado em um hospital universitário do Nordeste. Utilizou-se uma adaptação da técnica do desenho-história de Trinca entre setembro e outubro de 2017, sendo a amostra de nove crianças em idade escolar e pré-adolescentes. A pesquisa foi aprovada pelo Comitê de Ética em Pesquisa. Após análise temática, obteve-se três categorias, que destacaram a brinquedoteca como um recurso apoiador no cuidado a criança hospitalizada; mostraram as abordagens preferidas do brincar no período da internação; e citaram os profissionais e seus procedimentos. Foi constatado que o modo de abordagem dos profissionais influencia diretamente no tipo de experiência que será um determinado procedimento, e que o lúdico é uma estratégia fundamental no cuidado hospitalar, uma vez que corrobora para a melhoria dos estados físico, psicológico e emocional da criança.
\end{abstract}

DESCRITORES: Criança Hospitalizada; Cuidado; Ludoterapia.

\section{ABSTRACT}

To analyze the view of hospitalized children about playfulness as a strategy in care. Qualitative exploratory study of the participatory observational type realized at a university hospital in the Northeast. An adaptation of Trinca's drawing-history technique was used between September and October 2017, being the sample of nine school-age children and preadolescents. The research was approved by the Research Ethics Committee. After thematic analysis, three categories were obtained, which highlighted the playroom as a supportive resource in the care of hospitalized children; showed the preferred approaches to play during hospitalization; and cited the professionals and their procedures. It was found that the way professionals approach directly influences the type of experience that will be a given procedure, and that playfulness is a fundamental strategy in hospital care, as it corroborates the improvement of the physical, psychological and emotional states of the child.

DESCRIPTORS: Hospitalized Child; Care; Ludotherapy.

\section{RESUMEN}

Analizar la mirada de los niños hospitalizados sobre el juego como estrategia en el cuidado. Estudio exploratorio cualitativo observacional participativo, realizado en un hospital universitario del Nordeste. Se utilizó una adaptación de la técnica de historia del dibujo de Trinca entre septiembre y octubre de 2017, con una muestra de nueve niños en edad escolar y preadolescentes. La investigación fue aprobada por el Comité de Ética de Investigación. Resultados: Después del análisis temático, se obtuvieron tres categorías, que destacaron la sala de juegos como un recurso de apoyo en el cuidado de niños hospitalizados; mostró los enfoques preferidos para jugar durante la hospitalización; y citó a los profesionales y sus procedimientos. Se encontró que el modo de aproximación de los profesionales influye directamente en el tipo de experiencia que será un dado procedimento, y que el juego es una estrategia fundamental en la atención hospitalaria, ya que corrobora con la mejora de los estados físicos, psicológicos y emocionales del niño.

DESCRIPTORES: Niño Hospitalizado; Cuidado; Ludoterapia.

RECEBIDO EM: 05/01/2020 APROVADO EM: 06/01/2020

\section{Jéssica Íris Franco da Silva}

Enfermeira, Residente Multiprofissional em Saúde da Criança pelo Hospital Universitário Onofre Lopes/ Universidade Federal do Rio Grande do Norte. ORCID: https://orcid.org/0000-0001-8220-2172.

\section{Jéssica Barreto Pereira}

Enfermeira, Mestra em Enfermagem pela Universidade Federal da Paraíba- UFPB. ORCID: https://orcid.org/0000-00021274-6024. 


\title{
Simone Elizabeth Duarte Coutinho
}

Enfermeira, Doutora em Enfermagem pela Universidade Federal da Paraíba-UFPB. ORCID: https://orcid.org/0000-0002-8761-6056.

\author{
Jael Rúbia Figueiredo de Sá França \\ Enfermeira, Doutora em Enfermagem pela Universidade Federal da Paraiba- UFPB. ORCID: https://orcid.org/0000-0002-9968-5366.
}

\section{laponira Cortez Costa de Oliveira}

Enfermeira, Doutora em Administração Sanitária e Hospitalar pela Universidade de Estremadura. ORCID: https://orcid. org/0000-0002-1684-3956.

\section{Andressa Pereira do Carmo}

Enfermeira, Especialista em Saúde Coletiva pelas Faculdades Integradas de Patos. ORCID: https:/orcid.org/0000-0002-6718-1809.

\section{Elisabeth Luisa Rodrigues Ramalho}

Enfermeira, Residente Multiprofissional em Saúde da Criança pelo Hospital Universitário Onofre Lopes/ Universidade Federal do Rio Grande do Norte. ORCID: https://orcid.org/0000-0003-2469-4767.

\section{INTRODUÇÃO}

A hospitalização para a criança geralmente se torna um evento traumático devido a mudança em sua rotina e afastamento da família, o que contribui com o surgimento de sentimentos negativos, tais como angústia, tristeza e medo, podendo inclusive prejudicar seu prognóstico. A ocasião de estar num local limitado em que as rotinas reduzem a série de atividades que costumava desenvolver em casa, pode afetar o desenvolvimento natural da criança $a^{(1,2)}$.

$\mathrm{O}$ uso do lúdico durante esse processo é uma estratégia facilitadora da continuidade do tratamento, pois fortalece emocionalmente as crianças para os futuros procedimentos, por vezes exaustivos, invasivos e dolorosos. Desta forma, auxilia o enfrentamento e recuperação da criança, além da manutenção de sua qualidade de vida, apesar das condições de vulnerabilidade que a deixaram hospitalizada ${ }^{(3,4)}$.

As crianças são as melhores fontes de informação sobre suas próprias experiências e opiniões, expressando de diversas formas os seus pensamentos, podendo envolver expressões verbais e não verbais como a fala, choro, gestos, desenhos, entre outros, aspectos estes que devem ser considerados por quem está ao seu redor, em especial aos que prestam cuidados a elas ${ }^{(5)}$.

Geralmente, durante a hospitalização, a equipe não consegue identificar as dificuldades da criança e, nesta ocasião, a utilização de técnicas que possibilitem sua expressão poderá ser benéfica, a medida em que funciona melhorando o atendimento e avaliação de maneira mais adequada, envolvendo os sentimentos advindos do adoecimento ${ }^{(6,7)}$.

Considerando-se que o brincar deve ser uma ferramenta que auxilie o enfrentamento do processo de hospitalização e recuperação da criança, bem como a necessidade de respeitar as singularidades de cada uma delas, o estudo teve como questão norteadora: $\mathrm{O}$ lúdico influencia no cuidado das crianças no hospital? A partir disto, o objeto foi analisar o olhar de crianças hospitalizadas acerca do lúdico como estratégia no cuidado, a partir do relato das mesmas sobre a temática.

\section{METODOLOGIA}

Trata-se de um estudo exploratório de abordagem qualitativa do tipo observacional participante. Participou do estudo a população de crianças em processo de hospitalização entre o período de setembro e outubro 2017. A amostra constou de nove crianças em idade escolar e pré-adolescentes, identificados por pseudônimos alusivos aos personagens infantis ou ídolos que mais gostavam, mantendo seu anonimato.

Foram critérios de inclusão: ser de ambos os sexos; estar na faixa etária escolar ou pré-adolescência; independente do período de hospitalização, que tivessem tido contato com atividades lúdicas, podendo ou não ter histórico de internações anteriores no serviço; ser portador de qualquer diagnóstico, podendo este ser crônico ou não. E de exclusão: ter comprometimento neurológico e/ou cognitivo que impossibilitasse de desenhar e/ ou responder aos questionamentos; ou aqueles que não conseguissem prestar correspondência as questões da pesquisa por qualquer circunstância não inclusa no critério anterior.

Os dados foram coletados na brinquedoteca da clínica pediátrica de um hospital universitário do Nordeste, como também na beira do leito de algumas enfermarias quando os participantes se encontravam impossibilitados de sair. Foi utilizada uma adaptação fundamentada na técnica do desenho-estória descrita por Trinca em $1987^{(8)}$. As aplicações foram individuais, em ambiente silencioso, iluminado e confortável. Utilizou-se os seguintes materiais: folhas de papel em branco, lápis grafite, borracha, coleções de lápis de cor e de cera.

As crianças foram convidadas a fazer desenhos de forma espontânea, e em um dado momento, solicitava-se que produzisse desenhos que expressassem seu olhar sobre o brincar no hospital dada a sua condição clínica, considerando o conjunto de sentimentos envolvidos, através da representação de "coisas ruins" e/ou "coisas boas" do hospital. Em seguida, pediam-se esclarecimentos acerca dos 
mesmos - a estória. Também foram feitas indagações para esclarecimentos necessários a fim de aprofundar a compreensão do material. Nesta ocasião, foi utilizado um gravador de voz para registrar de maneira mais invariável as informações, com o intuito de obter o conteúdo a ser transcrito com minuciosa precisão.

Utilizou-se a análise temática em suas três etapas descrita por Minayo em $1992^{(9)}$, a saber: pré- análise; exploração do material; e tratamento dos resultados obtidos e interpretação. Foram obedecidos todos os preceitos éticos estabelecidos pela Resolução n. ${ }^{\circ}$ 466/12 do Conselho Nacional de Saúde (CNS), sendo este estudo aprovado sob parecer n. ${ }^{\circ}$ 2.261.165/2017 pelo Comitê de Ética em Pesquisa do Hospital Universitário Lauro Wanderley.

\section{RESULTADOS}

Participaram do estudo nove crianças em idade escolar e pré-adolescentes com média de idade de nove anos, dos quais cinco foram meninos e quatro meninas. O tempo médio de internação foi de 9,2 dias, tendo todos os participantes vivenciado atividades lúdicas. Destes, quatro já tiveram hospitalização anterior neste serviço, seis em outros serviços, e uma sendo a primeira vez em um hospital. Os diagnósticos variaram entre distúrbios cardiovasculares, respiratórios, hematológicos, endócrinos, renais e dermatológicos, além de casos de pré e pós-operatório.

Agrupou-se em três categorias as informações que destacaram a brinquedoteca como um recurso apoiador no cuidado a criança hospitalizada; as abordagens preferidas do brincar no período da internação; e os profissionais e seus procedimentos.

\section{A brinquedoteca como recurso apoiador no cuidado a criança hos- pitalizada}

Esta categoria abrangeu temas que reportaram a brinquedoteca como um apoio ao enfrentamento do processo saúde-doença, em que as falas demonstra- ram que a mesma oferece momentos de alegria e descontração, além de apontar o ambiente como mais agradável, envolvendo inclusive a família.

Os depoimentos, por unanimidade, destacam a satisfação em haver um espaço lúdico que proporciona oportunidade de ter bem-estar, humor e distração diante dos vários fatores estressantes da hospitalização. Quando questionadas por gostar da brinquedoteca e a frequência das idas, referiram:

"D-E-Z! De 0 a 10 eu gosto 10!!!" (TIANA, 07 anos)

"Já faz um monte de dia que eu vim [para o hospital], mas até que eu tô gostando daqui e da brinquedoteca." (MESSI, 12 anos)

"Eu gosto de lá da brinquedoteca, de alguns brinquedos, porque ficar só aqui direto nesse quarto é ruim." (AURORA, 10 anos)

"[Apontando para o desenho] Aquié o hospital, aqui é a máscara e aqui é a cama. Eu tô deitada aqui! [expressão negativa] [...] Vou sempre! Eu só num fui hoje, mas ontem eu brinquei demais." (ARIEL, 07 anos)

Alguns dos participantes já haviam tido hospitalização anterior no serviço, o qual teve a brinquedoteca reformada e recentemente inaugurada, ou em outros hospitais, e comparando-se o uso do lúdico nestes locais, quando questionados a respeito, relataram:

"N-Ã-O!!! Nada! Só ficava deitada na cama o tempo todinho." (ARIEL, 07 anos)

"Lá no outro hospital a gente só ia pra fora pra pintar..." (HULK, 10 anos)

"Adorei! [fala com muita empolgação] Já fui pra muitas brinquedotecas lá no Rio de Janeiro. A que eu mais gostei é essa do HU! Um hospital tão rico desse, lá era tudo pobre." (ESTRELA NEGRA, 07 anos).

Abordagens preferidas do brincar

\section{no período da internação}

Nesta segunda categoria, abordou-se as preferências do brincar nas determinadas faixas etárias e as atividades de recreação fora da brinquedoteca.

Notou-se que de acordo com a idade, as crianças apresentaram preferências distintas do brincar, variando desde jogos de habilidade, atividades de pintura e leitura, até brincadeiras populares, entre outros. Alguns também demonstraram possuir interação com outros colegas durante estes momentos. Quando questionados sobre suas preferências, relataram:
"Assistir os desenhos que eu gosto, jogar com os meninos." (ESTRELA NEGRA, 07 anos)
"De jogar bola, desenhar lá na brinquedoteca [...]." (HULK, 10 anos)
"Eu fiquei lá só assistindo e lendo livro. Semana passada eu li 5." (SHREK, 10 anos)
"Eu desenhei uma coisa que eu gosto muito daqui: uma dama! Eu também gosto de dominó, desses jogos de peça." (MESSI, 12 anos)
"Eu gosto do escorrego e do estetos- cópio. Fico lá brincando. Eu sei que já sou grande, mas eu gosto desse escorrego." (AURORA, 10 anos)
"[...] é a boneca lá da brinquedo- teca, a que eu gosto." (ARIEL, 07 anos)
"Adoleta." (HOMEM-ARANHA, 10 anos)
"Folha pra pintar e esses lápis." (TIANA, 07 anos)

Algumas demonstraram atração por atividades realizadas regularmente pelas brinquedistas e outros profissionais, como as oficinas, eventos em datas comemorativas e visitas de grupos religiosos.

\footnotetext{
"Ensinaram a fazer lá na brinquedoteca. Eu tenho um bocadinho, olha [mostra os origamis]." (HULK, 10 anos)

"[...] das festinhas que tem." (POCAHONTAS, 10 anos)
} 
"Minha mãe disse que quando eu tava brincando lá uma mulher da igreja passou dando livro." (HULK, 10 anos)

Verificou-se o anseio de alguns participantes por atividades que envolvem mídias como TV e Internet, além do desejo de poder usar, em seus leitos, os próprios brinquedos da brinquedoteca, quando encontram-se impossibilitados de ir até a mesma. Sendo as atividades de distração fora da brinquedoteca alvo de comentários dos participantes, os quais discorreram:

"Chegou esse mês, que da outra vez que eu vim num tinha. Tava em outro quarto, mas desde que a gente chegou essa televisão já tá aí." (HULK, 10 anos).

"É, de manhã eu mexo [Internet]. Ontem de $11 \mathrm{~h}$ da noite eu inventei de beber água só pra ir assistir The Voice [risos]." (SHREK, 10 anos) "Agora eu vou jogar! Baixei um "mói" de jogo na Internet." (POCAHONTAS, 10 anos)

"É porque não deixa trazer pra cá o dominó." (MESSI, 12 anos)

\section{Profissionais e procedimentos}

Diversos foram os relatos de situações vivenciadas que envolveram os profissionais e procedimentos, os quais foram agrupados neste tema.

Os procedimentos das punções venosas foram os mais mencionados, e para a maioria apresentam-se como eventos traumáticos, repletos de sentimentos de medo, angústia e choro, tendo várias vezes relacionado às experiências prévias, além de associarem a dor com o modo de abordagem do profissional envolvido, como demonstram as falas a seguir:

"Foi com força. Arrancou "meus cabelos" [pêlos]. Doeu mais agora. Eu já "botei" aqui, aqui, aqui e aqui. [mostra os vários locais dos acessos]." (HOMEM-ARANHA, 10 anos)

"Já tiraram sangue demais. Hoje de manhã "furaro" outra vez. Só hoje furei três vezes. Eu chorei porque tava dormindo." (HULK, 10 anos) "Adoro tomar comprimido! Melhor do que tomar remédio na veia né tia? Pra não ser furado. $O$ acesso tirou, mas tá aqui o roxo [aponta para o antebraço]. Passou 9 dias, mas só pode 7 né? Meu braço já tava paralisado." (SHREK, 10 anos)

"Desenhei a IN-JE-ÇÃO!!! Porque eu num gosto não, tia. Já levei um bocado de furada... Ontem mesmo fui lá pra aquela sala [sala de procedimentos], levei uma furada aqui nas costas pra tirar um aguinha da minha coluna, que agora eu esqueci o nome. Eu num gosto disso não, tia. 2uando eu cheguei furaram logo aqui [aponta] Foi naquela sala lá do corredor, eu só num chorei, mas fico logo agoniado. O que eu num gosto mesmo é de tirar sangue, essas coisas que fura, que dói." (MESSI, 12 anos) "Eu num gosto de furar não. Eu gosto só de tomar remédio na boca." (ARIEL, 07 anos)

"Eu desenhei a injeção... Porque dói! $E$ aqui eu desenhei uma menina doente." (POCAHONTAS, 10 anos)

E quando questionados se tinham ciência do motivo ou se alguém tinha explicado determinado procedimento, disseram:

"Não! Num sei. É pra fazer os exame, num é?" (HULK, 10 anos)

"Pra tomar o soro." (ARIEL, 07 anos)

"Pra tomar soro, pra "botar" remédio." (TIANA, 07 anos)

"Porque vai ter que botar a... [O pesquisador sugere: anestesia?] $E$ isso mesmo, ainda bem que eu já sei, acho que eu já sei como vai ser tudo. Tô só um pouquinho ansioso." (SHREK, 10 anos)

A sensibilidade, boa comunicação e criação de vínculo como construtores de uma melhor relação interpessoal entre profissional e criança foi percebida como benéfica no tocante ao cuidado humanizado, como nas falas abaixo:

"Eu tava achando graça [risos], na hora que ela veio tirar o acesso. Doeu, doeu um pouquinho, mas eu tava achando graça [risos]. Das enfermeiras que vieram cuidar de mim até agora ela foi a melhor... $e$ Kátia, porque elas são mais brincalhonas comigo. Ontem quando eu fui fazer a cirurgia já pedi logo pra ela vim ficar cuidando de mim." (SHREK, 10 anos)

"Eu tava muito nervoso, com medo, mas o povo até que foi bonzinho comigo. Brincaram... E pior que nem pegou, vou ter que fazer de novo pra fazer o exame. Agora vou ter que ir pra onde faz as cirurgias, pra botar uma coisa lá no meu nariz e eu não ver." (MESSI, 12 anos)

\section{DISCUSSÃO}

Durante a hospitalização, as crianças mantêm o anseio de realizar atividades inerentes a sua idade, as quais geralmente sofrem interferências das circunstâncias da evolução clínica. Todavia, deve-se considerar o crescimento e desenvolvimento de acordo com a etapa da vida, pois ao passo que, o ambiente hospitalar acarreta desafios para recuperação da saúde, também é local para este processo ${ }^{(10)}$.

Instituições de saúde à nível hospitalar tem investido na implementação de estratégias para construir ambiências que visam o acolhimento e harmonização, a fim de otimizar a assistência pediátrica, o que vem ocorrendo desde o advento da Política Nacional de Humanização. Dentre estas estratégias, destacam-se as atividades lúdicas que favorecem as relações interpessoais com os profissionais de saúde, facilitando todo o processo ${ }^{(11)}$.

A clínica pediátrica do referido hospital apresenta estrutura em conformidade com a Lei n. ${ }^{\circ} 11.104 / 2005$, a qual dispõe sobre a obrigatoriedade de instalação de brinquedotecas nas unidades de saúde 
que ofereçam atendimento pediátrico em regime de internação ${ }^{(12)}$. Este espaço é provido de brinquedos, jogos educativos, local para leitura e pintura, equipamentos de mídia como TV e computador, entre outros, ambos destinados a estimular as crianças e até mesmo seus acompanhantes a se entreterem.

Os depoimentos dos participantes evidenciam satisfação em ter um local onde possam se distrair e ter seu direito de brincar garantido, tornando-se evidente, principalmente para aqueles que já foram submetidos a outras hospitalizações, o quanto essa condição auxilia na promoção de bem-estar mental, emocional e até mesmo social, pois mesmo estando adoecida o seu desenvolvimento não para.

Ainda nesta perspectiva, estudo realizado com crianças em tratamento quimioterápico ${ }^{(7)}$, revelou que os brinquedos contribuem para a melhor adaptação ao meio hospitalar, sejam aqueles trazidos de casa, como também os jogos virtuais e internet. Além disso, aponta a brinquedoteca como um espaço essencial para auxiliar no enfrentamento do tratamento, tornando o hospital mais acolhedor, que apesar de ser o local idealizado para a realização das atividades lúdicas, os demais espaços como pátios, jardins e salas de recreação também servem para diversão na ausência da brinquedoteca.

Os benefícios do lúdico também são percebidos pelos acompanhantes, assim como demonstra outro estudo realizado com mães de filhos em tratamento oncológico $^{(13)}$, as quais afirmaram que estes tipos de atividades proporcionam relaxamento, alívio e redução do sofrimento, contribuindo de forma positiva neste processo.

Quanto à comunicação, produção semelhante ${ }^{(14)}$ realizada em uma brinquedoteca do Sul também demonstrou insatisfação das crianças acerca da ineficácia do diálogo com a equipe de enfermagem, principalmente no que diz respeito aos procedimentos a serem realizados, com destaque para punção venosa. As falas de Hulk e Shrek, por exemplo, expressam conhecimento deficiente sobre procedi- mentos aos quais foram submetidos.

Em concordância aos achados desta pesquisa, o uso de estratégias lúdicas, com o objetivo de preparo e tranquilização para procedimentos dolorosos, foi visto como positivo pelas crianças do estudo citado anteriormente ${ }^{(14)}$, as quais consideraram importante a comunicação dos profissionais para com elas, devendo abordá-las com cuidado e carinho.

O medo do desconhecido é evidentemente um fator que causa sofrimento e angústia na criança hospitalizada, deixando-a fragilizada, então é necessário que a mesma tome conhecimento de todos os componentes da hospitalização, incluindo os procedimentos, medicações e suas limitações, ocasionando assim, maior segurança acerca do cuidado oferecido $^{(15)}$. Neste sentido, é fundamental a adoção de atitudes de empatia e humanização por parte dos profissonais através da comunicação que é um instrumento valioso no cuidado ${ }^{(16)}$.

A literatura aponta a punção venosa como o procedimento mais frequente ao qual as crianças são submetidas durante sua hospitalização pra fins de administração de medicamentos, coleta de exames, entre outros ${ }^{(17)}$, o que é evidenciado pelos depoimentos de Homem-aranha, Hulk, Shrek, Messi, Aryel e Pocahontas, sendo bastante nítido que foram experiências traumáticas em suas vidas.

Estudo que comparou os comportamentos de crianças antes e após o uso do brinquedo terapêutico no procedimento de punção venosa periférica, evidenciou maior aceitação e adaptação ao procedimento após uso da ferramenta, havendo redução de alterações comportamentais, tais como: apelo pela presença materna, desvio do olhar ao profissional, aperto dos lábios, gritos, solicitação de interrupção do procedimento, choro e tensão muscular ${ }^{(17)}$.

Literatura relacionada menciona a obrigação da equipe de saúde em identificar as necessidades psicossociais das crianças e adolescentes hopsitalizados que advém de seus potenciais comprometidos e, desta forma, os cuidados pre- cisam ser ampliados para atender a todas estas necessidades ${ }^{(18)}$.

Ainda nesta perspectiva, os depoimentos de Messi e Shrek que evidenciam suas percepções do cuidado ao elogiarem dois membros da equipe de Enfermagem, demonstram que, apesar de naturalmente terem medo da dor, o modo de abordagem dos profissionais influencia diretamente no tipo de experiência que será aquele procedimento.

Este achado apresenta consonância com estudo ${ }^{(7)}$ que aponta o enfermeiro como um profissional que pode incorporar o brincar em suas práticas assistenciais durante as internações para as mais diversas finalidades.

\section{CONCLUSÃO}

Por meio desse estudo, fundamentado no olhar das crianças, constatou-se que o lúdico é uma estratégia fundamental no cuidado hospitalar, pois corrobora para a melhoria de seus estados físico, psicológico e emocional.

A própria ocasião da aplicação da técnica do desenho-estória se configurou como um momento de dispersão para os participantes, respeitando-se suas restrições e vulnerabilidade. Por isso, é importante ressaltar seus benefícios como contribuição inerente a comunidade científica da saúde, no que diz respeito a escuta qualificada dessa clientela.

Foi possível identificar os fatores atrelados para a criança do uso do lúdico no processo de hospitalização, tendo sido feita uma análise do quanto o brincar pode interferir no processo de cuidado no tocante a realização dos procedimentos necessários, apesar da prática do brinquedo terapêutico ainda ser deficiente no cenário, provavelmente devido à falta de capacitação dos profissionais.

Averiguou-se também, que existe incentivo contínuo para o desenvolvimento de atividades lúdicas, principalmente na brinquedoteca, além de serem reveladas as abordagens preferidas do brincar no hospital na perspectiva da criança.

No intuito de entender a importância 
do lúdico no cuidado com vistas à humanização, os resultados destacam que a criança como personagem principal neste processo, deve ser acolhida da melhor maneira e poupada sempre que possível de toda e qualquer experiência traumática em sua vida, e desta forma a equipe multiprofissional busca a excelência do cuidado.

As limitações do estudo se referem à abrangência, visto que foi realizado em apenas um hospital; a distração de alguns participantes durante a coleta de dados; além da interferência de outros pares nesta ocasião, como por exemplo, para administração de medicamentos.

\section{REFERÊNCIAS}

1. Costa TS, Morais AC. A hospitalização infantil: vivência de crianças a partir de representações gráficas. Rev enferm UFPE on-line [Internet]. 2017 [acesso em 07 nov 2017]; 11(Supl. 1): 358-67. Disponivel em: https://periodicos.ufpe.br/revistas/revistaenfermagem/article/view/11916.

2. Lima KYN, Santos VEP. Play as a care strategy for children with cancer. Rev Gaúcha Enferm. [Internet] 2015 [acesso em 07 nov 2017]; 36(2):76-81. Disponivel em: http://dx.doi. org/10.1590/1983-1447.2015.02.51514.

3. Santos SS, Alves ABS, Gomes A, Maia LFS. Ludoterapia as a tool in humanized nursing care. RECIEN [Internet]. 2017 [acesso em 09 dez 2019]; 7(21):30-40. Disponivel em: https://www. recien.com.br/index.php/Recien/article/view/240/327.

4. Moura FM, Costa Júnior AL, Dantas MSA, Araújo GCB, Collet N. Intervenção lúdica a crianças com doença crônica: promovendo o enfrentamento. Rev Gaúcha Enferm. [Internet]. 2014 [acesso em 12 nov 2017]; 35(2): 86-92. Disponivel em: http:// dx.doi.org/10.1590/19831447.2014.02.41822.

5. Vasques RCY, Mendes-Castillo AMC, Bousso RS, Borghi CA, Sampaio PS. Dando voz às crianças: considerações sobre a entrevista qualitativa em pediatria. Rev Min Enferm [Internet]. 2014 [acesso em 10 nov 2017]; 18(4): 1016-1020. Disponível em: http://www.dx.doi.org/10.5935/1415-2762.20140075.

6. Marques EP, Garcia TMB, Anders JC, Luz JH, Rocha PK, Souza S. Lúdico no cuidado à criança e ao adolescente com câncer: perspectivas da equipe de enfermagem. Esc. Anna Nery [internet]. 2016 [acesso em 10 dez 2019]; 20(3): e20160073. Disponivel em: http://www.scielo.br/scielo.php?script=sci_arttext\&pid=S141481452016000300218\&lang=pt.

7. Sposito AMP, Garcia-Schinzari NR, Mitre RMA, Pfeifer LI, Lima RAG, Nascimento LC. O melhor da hospitalização: contribuições do brincar para o enfrentamento da quimioterapia. Av. enferm. [Internet]. 2018 [acesso em 10 dez 2019]; 36 (3): 328337 Disponivel em: http://www.scielo.org.co/scielo.php?script=sci_arttext\&pid=S012145002018000300328\&lang=pt.

8. Trinca W. Investigação clínica da personalidade: o desenho livre como estímulo de apercepção temática. 2. ed. São Paulo: EPU; 1987.

9. Minayo MCS. O desafio do conhecimento: pesquisa qualitativa em saúde. São Paulo: Hucitec; 1992.

10. Souza ZS, Rolim, CLA. As Vozes das Professoras na Pedagogia Hospitalar: Descortinando Possibilidades e Enfrentamentos. Rev. Bras. Educ. Espec. [Internet]. 2019 [acesso em 19 dez 2019]; 25(3), 403-20. Disponível em: http://www.scielo.br/scielo.php?script=sci_arttext\&pi-

\section{$\mathrm{d}=\mathrm{S} 141365382019000300403 \&$ lang=pt.}

11. Ribeiro JP, Gomes GC, Thofehrn MB. Ambiência como estratégia de humanização da assistência na unidade de pediatria: revisão sistemática. Rev. Esc Enferm USP [Internet]. 2014 [acesso em 03 nov 2017]; 48(3):530-9. Disponivel em: http://www.scielo.br/pdf/reeusp/v48n3/pt_0080-6234-reeusp-48-03-530.pdf.

12. Brasil. Lei n. 11.104, de 21 de março de 2005. Dispõe sobre a obrigatoriedade de instalação de brinquedotecas nas unidades de saúde que ofereçam atendimento pediátrico em regime de internação. Diário Oficial da União, Brasília, 22 mar. 2005. Seção 1:1.

13. Oliveira ELN, Silva EC, Silva MFO, Coutinho SED, Sales AMC, Souza ATO, et al. Mothers' perception on recreational activities in the treatment of childhood cancer. International Archives of Medicine [Internet]. 2017 [acesso em 08 nov 2017];10(121):19. Disponivel em: http://imedicalsociety.org/ojs/index.php/ iam/article/view/2565/2155.

14. Santos PM, Silva LF, Depianti JRB, Cursino EG, Ribeiro CA. Os cuidados de enfermagem na percepção da criança hospitalizada. Rev Bras Enferm [Internet]. 2016 [acesso em 03 nov 2017] 69(4):603-9. Disponivel em: http://dx.doi.org/10.1590/ 0034-7167.2016690405i.

15. Costa TS, Morais AC. A hospitalização infantil: vivência de crianças a partir de representações gráficas. Rev enferm UFPE on-line [Internet]. 2017 [acesso em 20 dez 2019]; 11 (Supl. 1):358-67. Disponivel em: https://pdfs.semanticscholar.org/3a1d/17a5d47a426a8f3d0c70bc4765539fccbf49.pdf.

16. Broca PV, Ferreira MA. Processo de comunicação na equipe de enfermagem fundamentado no diálogo entre Berlo e King. Esc Anna Nery [Internet]. 2015 [acesso em: 03 nov 2017];19(3):467-74. Disponivel: http://www.scielo.br/scielo.php?script=sci_arttext\&pi$d=S 1414-81452015000300467 \&$ Ing=en\&nrm=iso\&tlng=pt.

17. Lemos ICS, Oliveira JD, Gomes EB, Silva KVL, Silva PKS, Fernandes GP. Brinquedo terapêutico no procedimento de punção venosa: estratégia para reduzir alterações comportamentais. Rev. Cuid. [Internet]. 2016 [acesso em 03 nov 2017]; 7(1): 1163-70. Disponivel em: http://dx.doi.org/10.15649/cuidarte. v7i1.303.

18. Moura FM, Costa Júnior AL, Dantas MSA, Araújo GCB, Collet N. Intervenção lúdica a crianças com doença crônica: promovendo o enfrentamento. Rev Gaúcha Enferm. [Internet]. 2014 [acesso em 12 nov 2017]; 35(2): 86-92. Disponivel: http://dx. doi.org/10.1590/19831447.2014.02.41822. 